\title{
A Case Analysis on the Adequacy of Work-Life Balance Practices in UK Small- and Medium-Sized Enterprises
}

\author{
Babatunde Akanji
}

\section{A B S T R A C T}

Objective: The purpose of this study is to examine whether work-life balance (WLB) practices are satisfactorily provided in UK small and medium-sized enterprises (SMEs) and the impact of the availability of these work-life policies on turnover intentions. A review of extant literature reveals scarce knowledge in this area of research and this study presents a rudimentary effort to fill this gap.

Research Design \& Methods: Using qualitative design, the data set comprised of indepth interviews with thirty-six employees working in small and medium-sized UK convenience stores and supermarkets with less than ninety employees.

Findings: Informal nature of human resource management policies emerged from the findings as one of the constraining forces impeding work-life agendas in SMEs and causing low staff retention in UK. Although other themes were found to contribute to retention challenges, however, these additional reasons were not independent, but all considered integrated.

Implications \& Recommendations: Consequently, the practical implication of devising ways to overcome WLB and retention deficiencies in this context were also explored.

Contribution \& Value Added: The originality of this work lies in studying the importance of WLB practices to some of these grass root businesses that make up a large proportion of the economy in the UK. As the limitation of this study is that it is wholly qualitative in nature, it is suggested that future research should rely on quantitative designs that provides more internally valid tests via computational techniques.
Article type: research paper
Keywords:
UK SMEs; work-life balance; convenience supermarkets; low staff retention; turnover intentions

JEL codes: A20

\section{Suggested citation:}

Akanji, B. (2017). A Case Analysis on the Adequacy of Work-Life Balance Practices in UK Smalland Medium-Sized Enterprises. Entrepreneurial Business and Economics Review, 5(3), 199-213. http://doi.org/10.15678/EBER.2017.050311 


\section{INTRODUCTION}

The delineation of work-life balance (WLB) initiatives has long been a topical issue in organisational studies with extensive research on practices and policies in either multinationals or globalised companies. There remains a paucity of similar studies within small and medium-sized enterprises (SMEs). Focussing on the continent of Europe, comprising of the European Union (EU) countries, SMEs amount to $99 \%$ of all enterprises, with claims that almost $42 \%$ of working class people in any EU member country were employed in this private sector businesses as far back as the 1960s (Mihail, 2004). One can only imagine the extremely huge number of owners and employees now involved in SMEs spread across the continent of Europe. In the United Kingdom for instance, (comprising of England, Scotland, Wales and Northern Ireland), there are about 4.5 million private small businesses of which $58.8 \%$ of the working population are in private sector employment, but with high records of $48.8 \%$ employee turnover rates (Barrett \& Burgess, 2008).

In London alone there are approximately 876000 SMEs and these small businesses have branches spread across the UK and contributing $67 \%$ to the nation's gross domestic product (Mihail, 2004). Reports on the astronomical growth of these family and nonfamily owned businesses also revealed that about 4.5 million UK private sector SMEs employed an estimated 23.8 million people as at 2011, and produced an estimated combined annual profit turnover of 15 billion GBP (Statistical release on the Department for Business Innovation and Skills, 2011). Given the large entrepreneurial involvement of small businesses in the UK from the foregoing data, it is evident that the benefit of adopting of WLB practices in these small and medium-sized organisations will contribute to developing and strengthening their capability to attract, motivate and retain skilled, flexible and adaptive workforce (De Cieri, Holmes, Abbott, \& Pettit, 2005).

There are a plethora of studies affirming ample research interest in WLB affairs of employees working in large corporations. This is because these big organisations are more visible and as a result, draw more attention of regulatory bodies, the media, academics and general public (De Kok, Uhlaner \& Thurik, 2006). Similar studies remain scarce at the level of personal or family-owned enterprises. Lavoie (2004) argued that this may be the reason for the under achievement of UK SMEs.

SMEs are defined as employing fewer than 250 people. They are termed 'micro businesses' and can constitute less than 10 people employed, or small ventures less than 50 workers and/or medium scale employing less than 250 people (Cassell, Nadin, Gray, \& Clegg, 2002). One of the primary themes in scholarly work-life research is employees' efforts in finding the right balance between their work and non-work roles. Organisations (whether big or small) are often scrutinised on how or why the implementation of a variety of WLB practices and policies are necessary for purposes of reducing negative work behaviours such as absenteeism, low job commitment, occupational stress and labour turnover (Gregory \& Milner, 2009). Labour turnover for instance, has to do with the ratio of the number of workers that had to be replaced in a given period to the average number of workers in an employment. It is common knowledge that employee turnover has a significant impact on any business productivity and profits (Lynch \& Tuckey, 2008). Potentially an organisation experiencing high turnover rates often incur overhead losses in areas of cost in replacing and training new staff. This implies the imperative for business owners 
and corporate entities to implement essential retention strategies. Sensibly, organisations that invest in creating supportive, comfortable and appealing working environment and work-life strategies can be said to tick the right boxes favourably in ensuring high levels of employee commitment and performance.

In light of the above, the research questions of this study are:

1. How do employees working in UK SMEs define and contextualise WLB?

2. What are the views of employees about the available of WLB policies in UK SMEs?

3. How do the (in) adequacy of work-life policies impact turnover intentions?

The research objectives of this paper run almost parallel to the questions stated above. Thus, the first objective is an attempt to enrich our understanding on the challenges of creating WLB benefits and programmes in UK small firms. Second, is to assess the level of employee withdrawal behaviours in reaction to work-life practices while the third relates to analysing work-life reforms that may impact retention strategies in small UK employments. Subsequently, the study is organised as follows. The next section is a literature review on WLB and SMEs. Following, is the section presenting the methodology used which is a qualitative approach for data collection and analysis proceeded by a presentation of study findings. Thereafter, the next part covers a detailed discussion on the research contributions derived from the findings. The last section highlights the conclusions.

\section{LITERATURE REVIEW}

In its broadest sense, WLB is a social concept conceived to suggest that paid work and personal life of a working adult should be seen less as competing priorities and rather as complementary elements of a full life (Manfredi \& Holliday, 2004). According to the general WLB framework diagrammatised in Figure 1, work-life integration underscores the extent to which an employee is equally engaged in and satisfied with his or her economic pursuits and active coordination of other domains of their life (Figure 1). In other words, it simply means an individual's capability to find a 'life rhythm' that enables them to combine their work with other domains of life (Felstead, Jewson, Phizacklea, \& Walters, 2002). This includes a state of 'satisfaction and good functioning at work and at home, with a minimum of role conflict' (Clark, 2000, p. 751). Therefore, from the perspective of SMEs, some of the advantages of adopting WLB policies is to accentuate positive outcomes for these small businesses in terms of employees' work commitment, satisfaction, performance and reduced withdrawal behaviours.

In view of the above, WLB policies in small scale businesses should be aimed at enabling employees to achieve life's aspirations through the accomplishment of greater management and control of all personal areas of life that are important to them. Despite these prospects open to SMEs to take advantage of designing and developing work-life policies that are crucial for employment and sustainable growth, Cegarra-Leiva, Sanchez-Vidal and Cegarra-Navarro (2012) found that managers of small enterprises in Europe are still slow to embrace WLB practices due to 'lack of resources, lack of skilled labour, and the lack of easy-to-use and affordable WLB solutions' that are readily adaptable to the business context of these organisations. Moreover, past but still reliable data provided by the European Foundation's survey on employment relations in UK micro and small enterprises suggests 
that employees of SMEs work more unsocial working hours, receive less training, less consultation and participation in decision making processes and more vulnerable to occupational stress. While it is known that in the United Kingdom, small firms make up the bulk of the business population (Barrett \& Burgess, 2008), the degree of imbalance between work and private lives of workers in this sector is of great concern. The antecedent of these challenges emanates from demographic changes in the nature and structure of working systems and family life arising from the active participation of women in the contemporary workforce which is blurring traditional gender role perspective that subject the women to domestication and family care responsibilities only (Brotheridge \& Lee, 2005).

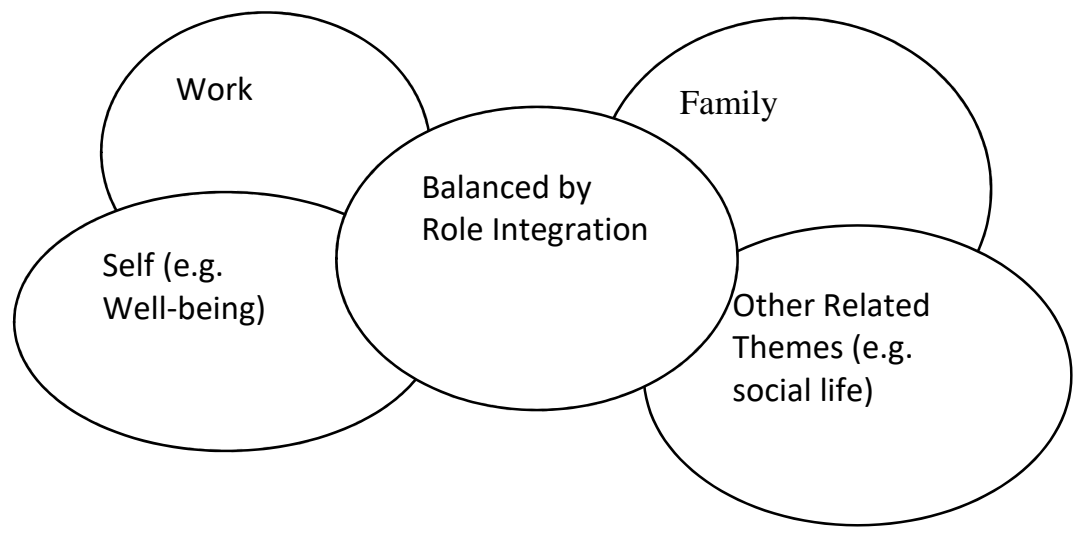

Figure 1. General WLB framework

Source: own study.

However, there is increasing clamour by British workers for a higher quality of life, welfare support that points towards addressing WLB solutions despite media and public knowledge of the ongoing UK budget cuts by the present government. Records provide that each year, job stress costs UK businesses an estimated 3.7 billion GBP and the loss of around 80 million working days (McVicar, Munn-Giddings, \& Seebohm, 2013). Such stress related issues have been attributed to both work and family related factors because many employees experience difficulties balancing their work obligations with home responsibilities (Özbilgin, Beauregard, Tatli, \& Bell, 2010). Within the $\mathrm{EU}$, the UK is known to have one of the longest working hours while Britons toil longer every week than other industrialised nations (Roberts, 2007). This invariably causes role pressures on employees working longer hours while some engage in 'inflexible work schedules' (Kossek, Kalliath, \& Kalliath, 2012). Focusing on SMEs in the UK, literature further reveals the lack of training and qualifications of managers' places limits on the adoption, development and functional operation of WLB practices in conformity with the 'EU/UK statutory minimum good practice guidelines' (Malik, McKie, Beatrie, \& Hogg, 2010). More evidence from literature suggests that most UK SME managers may economically adopt WLB practices based on overarching demands from their workers but decisions to offer them may be based on reciprocal expectations of extreme commitment and loyalty to employment (Dex \& Scheibl, 2001). Consequently, the rigid working conditions in SMEs across the UK breeds an environment 
where role pressures and conflict are possibly inevitable. This inter-role conflict outcomes will definitely have significant impact on UK small businesses. Most times, such employees are typically dissatisfied resulting in considerations of alternative employment (Ford, Heinen, \& Langkamer, 2007). Therefore, competing demands of work and domestic life degenerates into a tug-of-war situation in the lives of SME workers creating the notion that work-family conflict and intentions to leave are positively related with actual withdrawal from employment. Hence, the present study intends to provide further insights into the associated WLB challenges facing SMEs and explore retention solutions for this important sector to the UK economy.

\section{MATERIAL AND METHODS}

Semi-structured interviews were conducted and interpretative phenomenological analysis (IPA) used to gain ideographic insights of participants' lived experiences (Smith \& Osborn, 2003). The IPA like any other naturalistic research methodologies is designed to provide intricate and detailed understanding of how people construct meanings of social realities (Smith, 1996). This is a particularly useful interpretive design especially where there is little or no prior research enquiry on such topic (Cohen, Manion, \& Morrisonet, 2011). In essence, the underlying philosophical assumption of following a social constructivist paradigm is the belief that peoples' expressed thoughts are more vivid from verbal accounts as they try and make sense of their world (Gonzales, Brown, \& Slate, 2008). The advantage of this design is that it provides depths of understanding of the social reality being studied while a known weakness is the subjective nature of qualitative method.

A purposive sampling method was used to recruit all study participants. This method of non-probabilistic sampling is applied where qualitative data is collected using semi or unstructured interview protocols within a business case context (Saunders, Lewis, \& Thornhill, 2012). Thus, all key informants were selected based on their marital status, length of time at work (employed for a minimum of one year), age (20-49 years old) and educational status. The National Vocational Qualifications (NVQs) was the basic form of education that most participants had. Generally, NVQs is achieved through assessment and training based on the National Occupational Training Standards operational in the UK. The participants interviewed were all together (10 males and 26 females) of which 9 were unmarried, 5 were single parents, 8 were married with children and the rest divorced. Table 1 summaries the demographic data collected.

Table 1. Demographic characteristics of participants

\begin{tabular}{|l|l|c|c|}
\hline \multicolumn{1}{|c|}{ Description } & \multicolumn{1}{|c|}{ Range } & Mean & (SD) \\
\hline Age & $20-49$ years & 36 & 2.7 \\
\hline Work experience & $1-2$ years & 4 & 1.2 \\
\hline Age of children & 6-15 years & 9 & 22.2 \\
\hline Level of education & $\begin{array}{l}\text { primary school }(n=10) \\
\text { high school }(n=8) \\
\text { NVQs }(n=18)\end{array}$ & - \\
\hline
\end{tabular}

Source: own study. 
Before the research, formal permission was sort for site visits and granted by the management personnel and other important 'gate-keepers' that were of valuable contacts. Once access was formalized, the approval of time, place and frequency of visits was granted with full support from some member of staff designated to help facilitate the logistics needed to recruit subjects based on their availability and business convenience. Written consent, anonymity and confidentiality were strictly observed while each semistructured interview lasted for 45-60 minutes with all participants in their respective workplaces. The interviews were tape-recorded using predetermined but flexible interview protocol. Interviews questions included: what do you understand as work-life balance within the context of your job? Are there formal policies protecting your work-life affairs? What do your employers think about your life outside work? Are there any constraining factors to work-life provisions? What causes people to change jobs in UK small businesses? What more do you think can be done to improve the quality of life of employees in SMEs? The interviews continued until saturation point was reached. Thereafter all the recorded interviews were transcribed and afterwards read repeatedly for purposes of identifying the personal and situational themes that reflected points of interest from key descriptive words, comments and phrases from the interviews. In effect coding was pursued; emerging themes and subthemes that best captures the essential qualities of the transcribed interviews were identified. The final stage was translating the themes into a narrative account that then informed the main findings that emerged from the study.

\section{RESULTS AND DISCUSSION}

Initial inquiry were made on what the study participants understood by WLB and the following interpretations emerged.

\section{Scheduling Time Sensibly}

From the interview records, approximately $50 \%$ of the participants defined WLB as the ability to pay attention to family commitments as well as also succeeding at work. In other words, balancing work-life matters was viewed as having proportionate time for both life roles. Most of these participants here referred to the degree to which they can experience positive relationships between their work and family roles. This was said to arise from measuring the daily shifting weights of time allocated to work-life interjectory. The following quotations exemplify some shared views of the participants.

'Achieving balanced life between working and personal life is spending time with your family [...] and doing your own thing without compromising work. That's the best way I can describe WLB'. (Tony, convenience store attendant).

Another 40 year old shop keeper also iterated: 'it means you are working, but at the same time you're not just at work every day from the moment you get up until it's time for you to sleep at night, but you still have time to spend with your family and other loved ones'.

The preceding sample statements indicate that time management ranked significantly important in achieving a good work-life fit for these sets of employees. Some of the participants further acknowledged that although they work in small business firms where the economies of scale is comparably smaller to larger companies that generally have more capabilities of offering generous work-life policies, some of the participants argued that these family-friendly policies will definitely decrease negative spill-overs from workers' 
lives, leading to productivity and labour efficiency. In addition, there was a common perception that life presents numerous demands; hence, individuals have to prioritise and make choices through a judicious use of their limited resource such as - time.

\section{Staying Healthy}

About $30 \%$ of the participant defined WLB in terms of having to deal with health-related issues. To these sets of interviewees, WLB was defined in relation to the state of health and wellbeing that should not be compromised during the involvement with multiples roles of life. There was a general belief that a good work-life balance can provide a range of mental health benefits, including greater satisfaction with the quality of life, lower levels of work stress and physical improvements, derived from improved energy levels and longer life expectancy. For example, one of the female cashiers who works in a supermarket express said that: 'Although I work in a smaller supermarket when compared to the bigger ones such as Tescos, ASDA or Sainsbury's which I believe will have better practices in enhancing employees work-life integration, but I also think WLB means not compromising the quality of one's health and psychological wellness in a bid to create a leverage in both work-life activities...this is why I make sure my health is not compromised irrespective of the work-life policies provided by my employers'.

A few of the participants were of the view that when talking about a balanced work-life situation, discussions should not only centre on doing everything possible to produce completion and achievement of multiple role tasks successfully, but also have to include acknowledging self-care so that the employee's mind, soul and body are being refreshed in the process of engaging in daily work-life routines. One of the interviewees pointed out the possibility of trying to maintain a good work-life at the expense of staying healthy. In a particular interview, concerns were expressed about the pressures of an increasingly demanding work culture in the UK which was considered to be one of the biggest and most perhaps pressing challenge to mental health in the country. A supermarket attendant interviewed mentioned how the cumulative effect of increased working hours is impacting on the lifestyle of a huge number of British employees especially those working in small and medium scale businesses. Some of these key informants expressed their concerns of how they work overtime in order to meet financial obligations such as their mortgages and loans, but all these efforts also proves to damage their mental well-being. So these sets of participants conceptualized WLB as creating and maintaining supportive and healthy conditions.

\section{Leisure and Social Life Involvement}

Some of the participants expanded their definition of WLB beyond restrictions to work-family affairs only. These sets of views emerged from other household categories such as single-earner parents, co-habiting partners without children and singles. They acknowledged the importance of defining WLB from the perspective of active involvement in leisure pursuits and other social relaxation activities. This is why one of the unmarried participant commented that: 'At the moment, my perception of this thing called - WLB is about been able to participate in life's activities such as keeping my body fit through exercises in the same way I am here earning an income. But now, I don't have a balance anymore as work now tends to be a seven-day job because this is about the only medium-sized food store in this locality'. 
In addition, some other participants spoke about WLB as having 'fun time' in life such as travelling abroad on holidays, meeting with friends at the pub for few drinks, going to concerts, cinemas, voluntary work participation and even personal development activities. These various meanings ascribed to WLB presented insightful interpretations of the social concept regardless of individual demographics. Further enquiries on the extent to which WLB practices are available in SMEs revealed key barriers associated with satisfactory support for work-life integration in these UK SMEs. The main theme emerging from the findings centred on the informal nature of HRM policies influencing the range of WLB initiatives available to employees. It was revealed in some of the interviews that private or family enterprise owners prioritize business profits over the provision of well-documented work-life offers. The limited availability of WLB policies was ascribed to the small size of business, the hierarchy of management structure and the low skilled nature of the workforce employed in these small businesses. For example, one of the participants who works as a till cashier said that: 'We don't enjoy elaborate WLB policies which I think it is just one of the small food supermarkets established by the owners of which you can see we have a very small workforce [...] all I know is that I have 18 days holiday and work morning or night shifts based on business demands'.

Similar versions from other participants, especially from a few working in convenience stores, affirmed that their recruitment and working scheduling are marked by the absence of formalities. Most of the sales attendants at the counter narrated how staff retention is very low because of the feeling that they are often treated as a means to organizational ends because of the casual nature of their work. Further, some of these low-income workers especially the working parents expressed concerns of having little control over the way they manage to keep a balance between their jobs and family lives. A few participants felt most of them leave these small businesses once an opportunity is sighted to work in some of the biggest UK supermarkets such as Tesco, ASDA, Sainsbury's etc. as these mega supermarkets were perceived to offer more robust WLB packages. This findings resonates with earlier studies (e.g. Dex \& Scheibl, 2001; Cassell, Nadin, Gray, \& Clegg, 2002; Lavoie, 2004) whose findings reveal that firm size is an important predictor of the presence of work-life balance practices. For instance, Dex and Scheibl (2001) found that larger companies tend to adopt more work-family policies than smaller ones and organizations with perceived superior human resource management record may certainly provide more flexible labour opportunities. One of the male participants working in an Asian food store specifically mentioned the level of managerial favouritism as a major issue especially when worker's try to adjust their shift patterns to suit their work-life needs. He said among other things that: 'Sometimes my working shift is really a bottleneck because our manager prepare our job schedules on a weekly basis [...] a times the store manager sentimentally approves day shifts to some at the detriment of those of us with caring needs'.

In all, about $65 \%$ of all the interviewees were of the opinion that the inadequacy of WLB policies in their workplaces do not allow them to devote enough time to their family, personal health fitness and other social domains of life. On the whole, enquiries directed at exploring the range and scope of WLB initiatives available in these UK SMEs selected for the study, showed a level of doubt in the organizational culture supporting the WLB of employees. In sum, table 1 shows the overall responses of participants to questions asked about major types of WLB protocols under flexible work options, specialized leave policies 
and dependent care benefits perceived to be available, and if not available, the preferences of participants towards policies that are non-existent in these SMEs.

Table 2. WLB agendas

\begin{tabular}{|c|c|c|c|}
\hline WLB policies \& practices & Available & Not available & Will be interested if available \\
\hline \multicolumn{4}{|c|}{ Flexible work options } \\
\hline Part-time & Yes & - & - \\
\hline Flexitime & - & No & Yes \\
\hline Compressed hours & - & No & Yes \\
\hline Job sharing & - & No & Yes \\
\hline Home commuting & - & No & - \\
\hline \multicolumn{4}{|c|}{ Specialised leave policies } \\
\hline Study leave & - & No & Yes \\
\hline Maternity leave & Yes but minimal & - & - \\
\hline Paternity leave & - & No & Yes \\
\hline Casual leave & Yes & - & - \\
\hline \multicolumn{4}{|c|}{ Dependent care benefits } \\
\hline On site care facility (crèche) & - & No & Yes \\
\hline Care for sick dependent & - & No & Yes \\
\hline Professional counselling & - & No & Yes \\
\hline
\end{tabular}

Source: own study.

From the results above, many participants expressed concerns about the limited range of different organizational WLB policies available under the three broad categories tabulated. The participants exposed a high rate of interest for these small-medium businesses to make available more interventions aimed at facilitating flexibility, making available various specialized leave options, supporting employees with childcare responsibilities and rendering professional counselling to enhance workers' work-life nexus. Consequently, almost all the participants felt that providing only part-time, minimal maternity and casual leave options (Table 1) were some of the resultant causes of high turnover in the UK SMEs. Almost $90 \%$ of the interviewees at some point voiced out how turnover is a major issue for their employers having to bear unplanned costs of hiring and training new personnel, as well as the costs of not having departed employees working toward organizational sales performance. For instance, one of the female sales attendant working in one of the supermarkets with 60 employees said that: 'Since I have been working here for a year and a half now, some of the younger recruits hardly stay for six months before quitting [...] I can just imagine the turnover cost for exit and replacement that business needs to deal with in order to stay in business'.

Another theme that emerged from the study in relation to WLB shortages focused on the costs and benefits comparison associated with introducing a variety of these practices scheduled in Table 1. A female participant who works day shifts in a convenience store of only five employees observed that WLB costs could be most burdensome for small scale entrepreneurs. She made mention of how holding a job open for a woman on maternity leave could be problematic where she worked. There were also corroborated claims that implementing these WLB practices such as the provision of childcare subsidies or granting specialized leave policies will require administrative and procedural costs. This situation was perceived as been further exacerbated by the limited supply of financial resources available to 
these small business owners. While the benefits of adopting work-life practices were said to be needful to increase employee morale, productivity, customer engagement and reduced staff turnover, the overburdening cost of implementing new family-friendly policy systems was perceived difficult if the net impact will be negative on the overall business.

In a similar vein, another theme identified as low levels of qualifications and training of managers in SMEs emerged from some interviews. Three of the participants working in a supermarket of 30 employees in their separate interviews were persuaded that these characteristics of managers in SMEs restrict the development of WLB practices in their firms. Some of these entrepreneurs are viewed as having the mentality that workforce problems such as absenteeism or performance levels can be closely monitored because of the greater proximity and visibility of employees in small businesses. Hence, there is a general notion that small business owners don't see the need to implement the various WLB policies earlier highlighted (Table 1). Some of the participants gave evidence portraying some of these entrepreneurs as workaholics and adjudged to believe that working hard and long hours is the route to success. However, one of the male participant working in a grocery store felt business owners who engage in extreme business involvement to the detriment of their personal WLB needs is not only dangerous, but unhealthy. In addition, it was perceived as an inefficient way to run a business because if stifles creativity, kills motivation and increases withdrawal behaviours. Overall, all the participants perceived that viable ways of addressing these problems of WLB shortages in UK SMEs is for entrepreneurs to create a supportive work culture.

While the interviews with participants revealed some nagging problems confronting the sample of UK SMEs selected for this study, further enquires seeking responses on how best work-life practices can enhance employee retention were made. Most of the participants believed that there a number of staff retention strategies that SMEs can draw from and adapt to suit small business needs. It was established from the interviews that the existence of a WLB supportive culture for employees is a key factor for decreasing attrition rate in UK small businesses. The first theme that emerged from the aggregate data (i.e. interviews) as a solution to this turnover problem is the need for strong leadership that appreciates the value of WLB. A handful of participants felt that a relational approach to leadership should be embraced by UK business owners. Participants were of the opinion that this will go a long way to affect perceptions that allow employees to integrate their work with leisure, family time, travel, study and careers successfully. Some of the younger participants acknowledged the competitive pressures facing their employers, but at the same time think that UK entrepreneurs should exhibit patterns of affiliative leadership behaviours that puts people and their needs first. A few of the participants shared the belief that employees (whether skilled or unskilled labour) are more productive when allowed them to work flexible schedules.

For example, a female supermarket attendant feels that good business leaders should allow employees to job share with one person working the first half of a shift and another working the second half. There were also suggestions for small business owners to provide workers with a duty or a deadline and allow them work out their schedules to meet business objectives. In essence, almost all the participants were of the firm belief that there are many cost savings available to small business firms through the implementation of work-life bal- 
ance policies. The general assumption from the interviews was that work-life balance policies will improve staff retention in SMEs. Most interviewees believed that reducing staff turnover will lead to lower costs, as recruiting new staff is a costly process. However, the key informants of the study firmly confirmed supporting employees' work-life balance will improve performance, job satisfaction, and create positive employer branding.

This study mainly provided insights into an understanding of some challenges of WLB availability in UK SMEs. Evidence from the interviews revealed that the implementation of acceptable WLB practices are of major concern to study participants working in these small businesses. From the study, all the key informants defined work-life balance as a concept ranging from scheduling time appropriately for both work and family affairs, paying attention to healthy living as well as participation in social and leisure activities. This multiple meanings given to WLB broadens the interpretation of the concept that as for so long been restricted to focusing on the traditional family life and matrimonial household structures only. Emphases on WLB issues in literature are often placed on women with childcare responsibilities. This study findings debunks the sentimental assumption that women are primary targets of work-life balance debates (Gregory \& Milner, 2009). Therefore, the study findings is consistent with the views of Özbilgin et al., (2010, p. 5), who argued that knowledge enlargement in work-life research has become imperative because the concept is by no means a working mother's issue only. So irrespective of gender, WLB in its broadest sense, should mean an individual's satisfactory ability to juggle work and non-work activities that covers a wider spectrum of life's domain such as leisure activities, community participation, social life activities, religious and spiritual engagements and so on (Guest, 2002).

This study unveiled perceptions of inadequate provisions of WLB policies in UK SMEs. The results showed that there are a variety of work-life interventions ranging from atypical working arrangements, specialized leave options and dependent care benefits described in table 1 that the interviewees would like UK small business to adopt. The assumption is that employees will avail themselves of arrangements that are most suitable to them if a variety of these policies are available. The findings revealed the provision of only part-time work, casual leave policies and very minimal maternity leave opportunities (Table 1 ) in the sampled UK businesses of this study. In sum, the study findings revealed that the reasons for work-life policy shortages in UK small businesses includes low level of training and qualifications of small business owners on WLB agendas, the costs associated with introducing a wide range of WLB policies and lack of formalization of work-life practices.

Consequently, the informal nature of HR practices in SMEs as well as reports of UK entrepreneurs being perceived as extreme workaholics who do not see the need to embark on implementing a variety of family-friendly policies. These arises from their sentimental belief that employee 'presenteeism' which is the practice of being present at one's place of work at all cost is required for measuring high performance. However, Holt and Powell (2015) argued that a ubiquitous culture of 'presenteeism' is damaging productivity in UK workplaces at the moment. Thus, it is further contested that the value of prioritizing workers' health and well-being in UK SMEs should be a concept that is understood as a "fundamental business case for a productive, happy and healthy workforce" (Holt \& Powell, 2015). However, the study findings exposed the prevalence of WLB practices in UK small firms as scarce. Nevertheless, the phrase 'WLB' itself is part of popular discourse in the UK with the British Government making all efforts in developing a number of policies to promote a better integration 
between people's paid work and the rest of their lives through the introduction of various forms of statutory leave options, large investments in childcare agendas and addressing working hours by ensuring that statutory rights for any worker to request flexible working patterns is not compromised (www.gov.uk/work+life+balance+in+SMEs). But it is clear from the study that the inadequacy of WLB in UK SMEs is the main cause for the high turnover which can potentially harm the productivity of these grass root businesses especially in the area of employee work commitment. According to Robbins (1998), turnover is one of the organizational variables most closely related to job dissatisfaction. Thus, employee job satisfaction is crucial for business success and often linked to performance, organizational productivity and other issues, including turnover. Dissatisfied employees are prone to indulge in absenteeism and thereby increasing negative turnover (Toker, 2011, p. 156). In addition, Hughes and Bozionelos (2007) contested that current human resource practices most relevant to increasing work satisfaction have been found to be WLB practices, as they can help to foster the employees' quality of life and, as a consequence, workers will be more motivated and committed to the organization.

When employees cannot find balance between their job and non-working life, they can experience role conflict. This conflict is defined in WLB literature as "an interference of work and family roles that creates tension or problems for the individuals or as the direct result of incompatible pressures from an individual's work and family roles" (Moen, Kelly, \& Huang, 2008). Subsequently, work-life conflict can lead to stress and negative spill-overs from the home and a consequence of this is a decrease in productivity at work. Therefore, the variable significantly related to employee retention is the existence of a WLB supportive culture in UK SMEs. This result is consistent with previous literature that highlights the importance of organizational support for WLB in order to achieve high level of organizational and employee performance (Batt \& Valcour, 2003). Thus, an interesting dynamic in the case study is that almost all the participants were of the view that they were not sufficiently rewarded with WLB practices. Hence, it is essential for UK small business owners to take WLB policies and practices seriously and make every effort to implement them in their businesses.

\section{CONCLUSIONS}

This research presented various meaning of WLB and also highlighted employees' accounts on the limited range of WLB initiatives in UK SMEs. This was found to be the root cause of withdrawal behaviours from these small businesses when opportunities become available in larger UK mega-supermarkets such as Tescos, Siabury's and ASDA where it is believed that WLB policies are more formalized and pronounced. The study further identified some of the reasons for the lack of WLB opportunities in UK SMEs which emerged as the reason for high turnover problems. Hence, the issue of employee turnover raised a number of concerns in this study. It is a known fact that employees are important stakeholders in SMEs, but unfortunately after limited resources have been used in recruiting, training and developing the employees, they leave for greener pastures why their WLB needs will be met. Therefore, the study suggests an urgent need for small firms to engage in strategic planning and approaches to minimize turnover rates. The study also recommends that small business owners should provide training for all their workers irrespective of the fact that they are a low skilled workforce. It is important that SME managers and 
workers come together to find common WLB policies and practices for the common good of all. Ideally, this process should also be supported by the UK Government. Guidelines should be developed to ensure that employees working in SMEs are given duties that have realistic deadlines. The study also recommends that proper guidelines be developed for these low skilled workers to be incentivized for the extra number of hours or long working hours spent in such employments (Walker, Wang, \& Redmond, 2008). There may also be a need to consider the demand for flexibility within working patterns such as flexible hours, compressed hours, job share and so on (Table 1). On the whole, there is a need to ensure fairness and consistency in the implementation of WLB policies as a part of human resource management that can affect performance and retention of employees in this important sector of the UK economy. As the limitation of this study is that it is wholly qualitative in nature, it is suggested that future research should rely on quantitative designs that provides more internally valid tests via computational techniques.

\section{REFERENCES}

Barrett, R., \& Burgess, J. (2008). Small firms and the challenges of equality, diversity and difference. Equal Opportunities International, 27(3), 213-220.

Batt, R., \& Valcour, P.M. (2003). Human resource practices as predictors of work-family outcomes and employee turnover. Industrial Relations, 42(2), 189-220.

Brotheridge, C.M., \& Lee, R.T. (2005). Impact of work-family interference on general well-being: a replication and extension. International Journal of Stress Management, 12(3), 203-221.

Cassell, C., Nadin, S., Gray, M., \& Clegg, C. (2002). Exploring human resource management practices in small- and medium-sized enterprises. Personnel Review, 31(5), 671-695.

Cegarra-Leiva, D., Sanchez-Vidal, M., \& Cegarra-Navarro, G. (2012). Understanding the link between work-life balance practices and organizational outcomes in SMES: The mediating effect of a supportive culture. Personnel Review, 41(3), 359-379.

Clark, S.C. (2000). Work-family border theory: a new theory of work-family balance. Human Relations, 53, 747-770.

Cohen, L., Manion, L., \& Morrison, K. (2011). Research methods in education (7th ed.). Oxon: Routledge.

De Cieri, H., Holmes, B., Abbott, J., \& Pettit, T. (2005). Achievement and challenges for work-life balance in Australian organizations. International Journal of Human Resources Management, 16(1), 90-103.

De Kok, J.M.P., Uhlaner, L.M., \& Thurik, A.R. (2006). Professional HRM practices in family owned managed enterprises. Journal of Small Business Management, 44(3), 441-460.

Dex, S., \& Scheibl, F. (2001). Flexible and family-friendly working arrangements in UK-based SMEs: business cases. British Journal of Industrial Relations, 39(3), 411-431.

European Foundation Survey (2001). Jobs in EU Micro Firms: Summary, European Foundation for the Improvement of Living and Working Conditions. Dublin.

Felstead, A., Jewson, N., Phizacklea, A., \& Walters, S. (2002). Opportunisms to work at home in the context of work-life balance. Human Resources Management, 12, 54-76.

Ford, M.T., Heinen, B.A., \& Langkamer, K.L. (2007). Work and family satisfaction and conflict: a metaanalysis of cross-domain relations. Journal of Applied Psychology, 92(1), 57-80.

Gonzales, L., Brown, M.S., \& Slate, J.R. (2008). Teachers who left the teaching professions. A qualitative understanding. Qualitative Report, 13(1), 1-11. 
GOV.UK (2016). Work-life balance in SMEs. Retrieved on February 24, 2016 from www.gov.uk/work+life+balance+in+SMEs.

Gregory, A., \& Milner, S. (2009). Work-Life Balance: A matter of Choice. Gender, Work and Organisation, 16(1), 1-20.

Guest, E.D. (2002). Perspectives on the Study of Work-life Balance. Social Science Information, 41(2), 255-279.

Holt, M., \& Powell, S. (2015). Health and well-being in small and medium-sized enterprises (SMEs). What public health support do SMEs really need?. Perspectives in Public Health, 135(1), 49-55.

Hughes, J., \& Bozionelos, N. (2007). Work life balance as a source of jog satisfaction and withdrawal attitudes: An exploratory study on the views of male workers. Personnel Review, 36(1), 145-154

Kossek, E.E., Kalliath, T., \& Kalliath, P. (2012). Achieving employee wellbeing in a changing work environment: an expert commentary on current scholarship. International Journal of Manpower, 33(7), 738-753.

Lavoie, A. (2004). Work-life balance and SMEs: avoiding the 'one-sized-fits-all trap'. CFIB Research - July, 1-13.

Lynch, J.E., \& Tuckey, M. (2008). The policy turnover problem: fact or fiction?. Policing: An International Journal of Police Strategies \& Management. 31(1), 6-18.

Malik, F., McKie, L., Beatrie, R., \& Hogg, G. (2010). A toolkit to support human resource practice. Personnel Review, 39(3), 287-307.

Manfredi, S., \& Holliday, M. (2004). Work-life balance: an audit of staff experience at Oxford Brookes University. Oxford: The centre of diversity policy research, Oxford Brookes University.

McVicar, A., Munn-Giddings, C., \& Seebohm, P. (2013). Workplace stress interventions using participatory action research designs. International Journal of Workplace Health Management, 6(1), 18-37.

Mihail, D.M. (2004). Labour flexibility in Greek SMEs. Personnel Review, (33)5, 549-560.

Moen, P., Kelly, E., \& Huang, R. (2008). Fit inside the work-family black box: an ecology of the life course, cycles of control reframing. Journal of Occupational and Organizational Psychology, 81, 411-433.

Özbilgin, M.F., Beauregard, T.A., Tatli, A., \& Bell, M.P. (2010). Work-Life, Diversity and Intersectionality: A Critical Review and Research Agenda. International Journal of Management Reviews, 13(2), 1-22.

Robbins S.P. (1998). Organizational Behaviour. New Jersey: Prentice-Hall International.

Saunders, M., Lewis, P., \& Thornhill, A. (2012). Research methods for business students (6th ed.). London: Prentice Education Limited.

Statistical release on the Department for Business Innovation \& Skills (2011). Statistical data. Retrieved on August 4, 2015 from http://stats.bis.gov.uk/ed/bpe/ on 04/08/2015.

Smith, J.A., \& Osborn, M. (2003). Interpretative phenomenological analysis. In J.A. Smith (Ed.), Qualitative Psychology: A practical guide to research methods (pp. 51-80). London: Sage Publications.

Smith, J.A. (1996). Beyond the divide between cognition and discourse: using interpretative phenomenological analysis in health psychology. Psychology and Health, 11, 261-271.

Toker, B. (2011). Job satisfaction of academic staff: an empirical study on Turkey. Quality Assurance in Education, 19(2), 156-169.

Walker, E., Wang, C., \& Redmond, J. (2008). Women and work-life balance: is home-based business ownership the solution?. Equal Opportunities International, 27(3), 258-275. 


\section{Author}

\section{Babatunde Akanji}

Lecturer at the Department of Human Resource Management, Elizade University (Nigeria). He obtained his first degree in Law from the University of Ilorin (Nigeria). Thereafter a Masters in International Strategic Management from Staffordshire University (UK) and PhD in Human Resource Management from the University of Wales (UK). His research interests includes work-life balance, occupational stress, leadership and entrepreneurship.

Correspondence to: Dr. Babatunde Akanji, Elizade University, Wuraola Ojo Avenue, P.M.B 002; Ilara-Mokin, Ondo State, Nigeria; email: babatunde.akanji@elizadeuniversity.edu.ng

\section{Copyright and License}

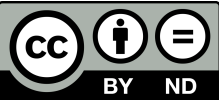

This article is published under the terms of the Creative Commons

Attribution - NoDerivs (CC BY- ND 4.0) License http://creativecommons.org/licenses/by-nd/4.0/

Published by the Centre for Strategic and International Entrepreneurship - Krakow, Poland 
